\title{
Evaluation of new volatile compounds as lures for western flower thrips and onion thrips in New Zealand and Spain
}

\author{
D.A.J. Teulon ${ }^{1}$, C. Castañé ${ }^{2}$, M-C Nielsen ${ }^{1}$, A.M. El-Sayed ${ }^{1}$, M.M. Davidson ${ }^{1}$, \\ R. Gardner-Gee 3 , J. Poulton ${ }^{3}$, A.M. Kean ${ }^{3}$, C. Hall ${ }^{3}$, R.C. Butler ${ }^{1}$, C.E. Sansom ${ }^{4}$, \\ D.M. Suckling ${ }^{1}$ and N.B. Perry ${ }^{4}$ \\ ${ }^{1}$ The New Zealand Institute for Plant \& Food Research Limited, Private Bag 4704, \\ Christchurch 8140, New Zealand \\ ${ }^{2}$ Institut de Recercai Tecnologia Agroalimentaries (IRTA), Ctra. de Cabrils, Km 2, \\ 08348 Cabrils (Barcelona), Spain \\ ${ }^{3}$ The New Zealand Institute for Plant \& Food Research Limited, Private Bag 92169, \\ Auckland 1142, New Zealand \\ ${ }^{4}$ The New Zealand Institute for Plant \& Food Research Limited, Department of Chemistry, \\ University of Otago, PO Box 56, Dunedin 9054, New Zealand \\ Corresponding author: david.teulon@plantandfood.co.nz
}

\begin{abstract}
Two glasshouse trials in a capsicum crop near Warkworth, New Zealand, in January 2011 and two field trials in a nectarine orchard near Lleida, Spain, in July 2013 were undertaken to determine if trap capture of Frankliniella occidentalis (western flower thrips, WFT) and Thrips tabaci (onion thrips, OT) could be increased by alternative volatile compounds beyond the known thrips attractant, methyl isonicotinate (MI). On blue sticky board traps in the crop in New Zealand, none of six alternative compounds tested caught more thrips (mostly WFT, OT and two other species) than the Control traps. In contrast to MI, catches with the alternative lures were mostly significantly lower. For both trials in the orchard in Spain using white water traps, the highest numbers of WFT and OT were caught in traps with MI, significantly higher than the Control (up to $11 \times$ for both species) and higher than most of the nine alternative odour compounds tested.
\end{abstract}

Keywords Frankliniella occidentalis, Thrips tabaci, lure, methyl isonicotinate, LUREM-TR, nectarine, capsicum.

\section{INTRODUCTION}

Methyl isonicotinate, the active ingredient (ai) of the thrips monitoring technology LUREM-TR (Teulon et al. 2011; Koppert 2014; Pherobank 2014), and ethyl isonicotinate have been shown to be effective lures for increasing the behavioural responses of several thrips species (Thysanoptera: Thripidae) in traps or a Y-tube olfactometer in comparison to other active compounds (Teulon et al. 2007a,b; Davidson et al. 2007, 2008; Wogin et al. 2010; Broughton et al. 2012; Muntyan et al. 2013). However, new potential active ingredients for thrips lures are continually being discovered (e.g. El Sayed et al. 2014), and it is expedient to benchmark the standard ai against new and 
alternative ones to improve lure efficacy for thrips monitoring and perhaps pest management through mass trapping (e.g. Sampson \& Kirk 2013) and lure and infect (e.g. Niassy et al. 2012).

Key considerations for selecting an optimal ai for a thrips lure include: (1) efficacy against thrips - the ai must increase trap capture of one or more key thrips pest species, (2) non toxic the ai must be safe for human use, (3) volatility - the ai must be able to vaporise under ambient trapping conditions and (4) cost - the ai must be relatively inexpensive to fit into established pest monitoring programmes.

First and foremost, the ai must attract the targeted thrips species. In this paper four trials are described, two in a capsicum glasshouse in New Zealand and two in a nectarine orchard in Spain, to compare the efficacy of methyl isonicotinate against several alternative active ingredients for use in thrips lures. The trial in New Zealand targeted the response of the cosmopolitan glasshouse inhabiting thrips, Frankliniella occidentalis (western flower thrips, WFT) and Thrips tabaci (onion thrips OT), to a range of lactone compounds identified from ripening peach fruits and some found to be attractive to the New Zealand flower thrips (Thrips obscuratus Crawford) (El-Sayed et al. 2014). The trials in Spain targeted the response of WFT and OT to a wider range of potential active ingredients including selected peach fruit volatiles ( $\gamma$-decalactone, $\delta$-decalactone, 6 -amyla-pyrone), known thrips attractants including ethyl nicotinate (Penman et al. 1982; Teulon et al. 1993), cis-jasmone (Teulon et al. 2007a; El-Sayed et al. 2009) and methyl anthranilate (Murai et al. 2000), floral odours (methyl jasmonate) (Teulon et al. 2007a) or vegetable fruit odours (2-isobutyl3-methoxypyrazine, methyl pyrazinoate). The WFT aggregation pheromone (Hamilton et al. 2005) was not included in these trials as its activity is largely restricted to one thrips species.

\section{METHODS}

\section{New Zealand glasshouse trials}

Two trials were conducted in one-half of a 12,560 $\mathrm{m}^{2}$ capsicum (Capsicum annuum) glasshouse near Warkworth ( $\left.36^{\circ} 24^{\prime} 29^{\prime \prime} \mathrm{S}, 174^{\circ} 36^{\prime} 58^{\prime \prime} \mathrm{E}\right)$ from 17-21 January (Trial 1) and 24-28 January (Trial 2) 2011 to test the response of thrips to methyl isonicotinate and six alternative volatile compounds. Blue HORIVER sticky board traps, $10 \times 25 \mathrm{~cm}$ (Koppert Biologicals, The Netherlands) were hung $10-20 \mathrm{~cm}$ above the crop canopy, $10 \mathrm{~m}$ apart and at least $20 \mathrm{~m}$ from the glasshouse wall in a $3 \times 5$ incomplete Latin square. In the centre of each sticky trap a $10 \mathrm{~mm}$ diameter hole was pre-drilled and a cotton dental roll (size 2, South Island Medical Wholesalers, New Zealand, $3.5 \mathrm{~cm}$ long) placed in the hole to which $1 \mathrm{ml}$ (in most cases - see Table 1) of the odour compound was added. All the sticky traps were hung in the greenhouse before treatments were applied. In each trial, three different alternative odour compounds, a positive control (MI) and a neutral control (water) were included. The trials ran from Monday to Friday. All traps were replaced after 2 days, giving two sets of traps per trial (Mon-Wed, Wed-Fri). The numbers of thrips caught on each trap were counted directly on the traps using a stereo microscope $(>100 \times$ magnification). All thrips from the 20 traps (five from Mon-Wed, five from Wed-Fri for each Trial) from the middle row (i.e. one-third of the traps) were removed, slide mounted and identified to species/sex under a compound microscope (>400× magnification) using Mound \& Walker (1982) and Moritz et al. (2004). Only the results of total number of thrips were analysed.

\section{Spain orchard trial}

Two field trials were conducted in a nectarine (Prunus persica var. Fantasia) orchard near Lleida, Spain ( $\left.41^{\circ} 34^{\prime} 55^{\prime \prime} \mathrm{N}, 0^{\circ} 25^{\prime} 59^{\prime \prime} \mathrm{E}\right)$ between 1-3 July (Trial 1) and 3-5 July (Trial 2) 2013 to test the response of WFT and OT to ten volatile compounds. Air temperatures were $15.6^{\circ} \mathrm{C}$ (mean daily minimum) and $33.1^{\circ} \mathrm{C}$ (mean daily maximum). The fruit on the trees was immature. The water traps used were 2 litre plastic containers $(178 \times 178 \times 80 \mathrm{~mm})$ (Viscount Plastics, New Zealand) laid out in incomplete Latin square designs. Traps were spaced at $20 \mathrm{~m}$ intervals in a $5 \times 7$ grid (Trial 1) and a $5 \times 6$ grid (Trial 2). The water traps were placed on top of inverted brown/terracotta coloured 
plant pots ( $16 \mathrm{~cm}$ high) on the ground, just below the trees. Each trap contained approximately 1.7 litres of water and a few drops of detergent. A $4 \mathrm{ml}$ glass vial (Arthur Holmes Ltd, New Zealand) was suspended over the middle of each water trap with a piece of wire $(0.5 \mathrm{~mm}$ diameter). Each vial contained a roll of filter paper $(50 \times 60 \mathrm{~mm}$, Whatman International, England) that projected $\mathrm{ca} 1 \mathrm{~cm}$ above the top of the vial to create a wick. Five and four volatile compounds were included in Trial 1 and Trial 2 , respectively, as well as a positive (MI) and a neutral control (water) (Table 1).

Trials were run over $48 \mathrm{~h}$. Traps were placed in the field and the appropriate treatment vial added. All insects in the trap were extracted within $24 \mathrm{~h}$ by sieving the water through a fine mesh. All thrips were removed, counted and stored in $96 \%$ ethanol. A subsample was mounted on microscope slides for identification using the following criteria: (a) for $\leq 50$ per trap, all thrips were mounted, (b) for 51 to 500 per trap, 50 thrips were mounted. The number of thrips for each species and their sex was determined and the number per trap estimated. Thrips were identified according to Moritz et al. (2004).
Compounds tested in all four trials, their purity $(\%)$ and the amount $(\mathrm{ml})$ used is listed in Table 1.

\section{Statistical analyses}

Data for the four trials were analysed separately using a Poisson-gamma hierarchical generalised linear model approach (McCullagh \& Nelder 1989; Lee et al. 2006). This used a Poisson distribution for the fixed effects (treatments) and a gamma distribution for random effects, both with logarithmic links. The analyses of data for the species included the $\log$ (number in mounted sub-sample/total on trap) as an 'offset' (McCullagh \& Nelder 1989), to adjust results to estimated numbers of each species/sex per trap. The importance of possible random effects (such as the two sets of traps for the glasshouse trials (i.e. Mon-Wed and Wed-Fri.) and spatial position for the Spanish trials) were explored by fitting the model with various combinations of the effects, and comparing the models with $\mathrm{X}^{2}$ tests of the change in deviance, as implemented in GenStat's HGRTEST procedure (GenStat Committee 2013a). For the glasshouse trials, there were important differences between traps

Table 1 Treatments used in the capsicum glasshouse (New Zealand) and nectarine orchard (Spain). All compounds were applied as $1 \mathrm{ml}$ of liquid, except cis-jasmone that was applied at $0.2 \mathrm{ml}$ per dispenser due to a limited amount available and methyl pyrazinoate that was dissolved in absolute ethanol to produce $1 \mathrm{ml}$ of solution at $0.21 \mathrm{~g} / \mathrm{ml}$.

\begin{tabular}{llccc}
\hline Compound & CAS number & $\begin{array}{c}\text { Glasshouse } \\
\text { trials }\end{array}$ & $\begin{array}{c}\text { Nectarine } \\
\text { trials }\end{array}$ & Purity \\
\hline Water (control) & & $1 \& 2$ & $1 \& 2$ & $100 \%$ \\
methyl isonicotinate (MI) & $2459-09-8$ & $1 \& 2$ & $1 \& 2$ & $>98 \%$ \\
Y-decalactone & $706-14-9$ & 1 & 1 & $98 \%$ \\
Y-heptalactone & $105-21-5$ & 1 & & $\geq 98 \%$ \\
6-amyl-a-pyrone & $27593-23-3$ & 1 & 2 & $>96 \%$ \\
Y-octalactone & $104-50-7$ & 2 & & $\geq 97 \%$ \\
S-decalactone & $705-86-2$ & 2 & 2 & $\geq 98 \%$ \\
Y-nonalactone & $104-61-0$ & 2 & & $\geq 98 \%$ \\
cis-jasmone & $488-10-8$ & & 1 & $>85 \%$ \\
methyl jasmonate & $39924-52-2$ & & 1 & $95 \%$ \\
methyl anthranilate & $134-20-3$ & & 1 & $>98 \%$ \\
2-isobutyl-3-methoxypyrazine & $24683-00-9$ & & 2 & $99 \%$ \\
methyl pyrazinoate & $6164-79-0$ & & 2 & $21 \%$ \\
ethyl nicotinate & $614-18-6$ & & 2 & $99 \%$ \\
\hline
\end{tabular}


on Mon-Wed and Wed-Fri, whilst for both Spanish field trials no spatial random effects were required. For all sets, the dispersion was estimated, and in addition for the Spanish trials, it was found necessary to adjust for aggregation of thrips by including a saturated random effect for traps. Once the important random effects had been identified, the model was re-fitted including these effects, and the overall treatment effect assessed similarly to the random effects, using GenStat's HGFTEST procedure. Comparisons of each treatment with the Control or MI were assessed by including a contrast that was assessed similarly to the overall treatment effect.

In the results, mean numbers per trap and associated 95\% CIs were obtained on the link (logarithmic) scale, and back-transformed to counts. For the species/sexes, these means were obtained by setting the offset to $\log (1)$, thus giving estimated mean counts per trap. All analyses were carried out with GenStat (GenStat Committee 2013b).

\section{RESULTS}

\section{New Zealand glasshouse trials}

For both trials, total thrips trap catch varied significantly between the treatments $(\mathrm{P}<0.001$ and $\mathrm{P}=0.001$ for Trials 1 and 2, respectively). For Trial 1, all compounds tested caught more than the Control, significantly so $(\mathrm{P}<0.05)$ for $\mathrm{MI}$,
Y-heptalactone and 6-amyl-a-pyrone (Table 2). All of the alternative compounds caught significantly less than MI. In Trial 2, all compounds caught more than the Control, with MI and $\gamma$-octalactone significantly more. However, all of the alternative compounds caught fewer thrips than MI, with $\delta$-decalactone significantly less $(\mathrm{P}<0.001)$. Of the 327 thrips mounted and identified, $46 \%$ were WFT, $11 \%$ were OT, $23 \%$ were other Thrips spp. (mostly NZFT), and 20\% were Frankliniella intonsa.

\section{Spain nectarine orchard trials}

In all, 436 thrips were caught in Trial 1 and 1043 in Trial 2, which equated to 12.5 and 34.8 thrips per trap respectively. Around $82 \%$ of the total thrips counted in water traps in Trial 1 and 78\% in Trial 2 based on the sub-sampling criteria (see above) were mounted on microscope slides and identified to species and sex. WFT females were the most common (54\% in Trial 1, 43\% Trial 2) of those identified. WFT males made up around $19 \%$ and $32 \%$, and OT $21 \%$ and $17 \%$ in Trial 1 and 2, respectively. Thrips major females and males made up less than $6 \%$ of those identified in either trial. Numbers of total thrips (sexes combined), WFT (both sexes) and OT (females only) only were analysed formally.

Total thrips numbers varied significantly between treatments in both trials $(\mathrm{P}=0.010$ and $\mathrm{P}=0.001$ for Trial 1 and Trial 2, respectively for the

Table 2 Mean number of total thrips per trap (95\% CI) and ratios of mean counts to the Control or methyl isonicotinate (MI) for the two New Zealand (capsicum greenhouse) trials. Bold ratios are larger $(\mathrm{P}<0.05)$ and italic ratios are smaller $(\mathrm{P}<0.05)$ than Control or MI.

\begin{tabular}{|c|c|c|c|c|c|c|}
\hline \multirow[b]{3}{*}{ Treatment } & \multicolumn{3}{|c|}{ Trial 1} & \multicolumn{3}{|c|}{ Trial 2} \\
\hline & \multirow[b]{2}{*}{ Mean } & \multicolumn{2}{|c|}{ Ratio to } & \multirow[b]{2}{*}{ Mean } & \multicolumn{2}{|c|}{ Ratio to } \\
\hline & & Control & MI & & Control & MI \\
\hline Control & $7.2(3.7,13.9)$ & - & 0.3 & $17.0(9.8,29.5)$ & - & 0.6 \\
\hline methyl isonicotinate & $26.0(14.6,46.4)$ & 3.6 & - & $30.8(18.5,51.3)$ & 1.8 & - \\
\hline Y-decalactone & $9.0(4.7,17.1)$ & 1.3 & 0.3 & - & - & - \\
\hline Y-heptalactone & $12.5(6.8,23.1)$ & 1.7 & 0.5 & - & - & - \\
\hline 6-amyl-a-pyrone & $15.8(8.7,28.9)$ & 2.2 & 0.6 & - & - & - \\
\hline Y-octalactone & - & - & - & $25.2(14.9,42.4)$ & 1.5 & 0.8 \\
\hline$\delta$-decalactone & - & - & - & $12.8(7.2,23.0)$ & 0.8 & 0.4 \\
\hline Y-nonalactone & - & - & - & $23.0(13.6,39.0)$ & 1.4 & 0.7 \\
\hline
\end{tabular}


overall test). For both trials, the highest numbers of total thrips were caught in the traps with MI, significantly higher than those caught on the Control $(\mathrm{P}<0.05$, Table 3$)$. Significantly more total thrips were caught in traps with $\gamma$-decalactone and $\delta$-decalactone in Trial 1 , and with methyl pyrazinoate and ethyl nicotinate in Trial 2 than in the Control traps. However, in each case, traps with these treatments caught around half the numbers of total thrips in traps with MI.

For WFT, there were significant differences between treatments in numbers of females in both trials $(\mathrm{P}=0.006$, and $\mathrm{P}=0.038$, Table 4) and in numbers of males in Trial $2(\mathrm{P}=0.007$, Table 5). However, numbers of males in Trial 1 did not vary so strongly ( $\mathrm{P}=0.056$ respectively), although numbers were highest in traps with MI and $\delta$-decalactone $(10 \times$ and $12 \times$ more than Control traps respectively). For WFT females, traps with MI caught the most thrips (11.5 $\times$ $(\mathrm{P}=0.009)$ and $3.4 \times(\mathrm{P}=0.007)$ more than Control traps in Trial 1 and 2, respectively). In Trial 1, numbers of both sexes were higher for treatments $\gamma$-decalactone and $\delta$-decalactone than for the Control $(\mathrm{P}=0.047,0.046$ for females,
$\mathrm{P}=0.072,0.028$ for males, respectively). However, numbers for treatments other than $\delta$-decalactone were lower than those for MI (not significantly in all cases). In Trial 2, only numbers caught with MI were significantly higher than those for the Control ( $\mathrm{P}=0.007$ females, $\mathrm{P}=0.009$ males).

Trap capture of OT females was significantly different between the treatments in both trials $(\mathrm{P}=0.020$ and $\mathrm{P}<0.001$, respectively, Table 6). In Trial 1, only MI caught significantly more than the Control $(\mathrm{P}=0.010)$, whilst in Trial 2, $\mathrm{MI}$ and ethyl nicotinate caught significantly more than the Control $(\mathrm{P}<0.001)$. However, numbers caught with ethyl nicotinate were only just above half of those caught with MI.

\section{DISCUSSION}

This work substantiates the relative greater utility of MI, compared to a range of alternative volatile compounds, for increasing trap capture of the key cosmopolitan pest thrips species, WFT and OT, and reinforces previous work comparing MI with a larger range of volatile compounds (e.g. Teulon et al. 2007a; Davidson et al. 2007, 2008). Additionally, MI has activity against a

Table 3. Mean number of total thrips per trap (95\% CI) and ratios of mean counts to the Control or methyl isonicotinate $(\mathrm{MI})$ in Spain (nectarine orchard) trials. Bold ratios are larger $(\mathrm{P}<0.05)$ and italic ratios are smaller $(\mathrm{P}<0.05)$ than Control or MI.

\begin{tabular}{|c|c|c|c|c|c|c|}
\hline \multirow[b]{3}{*}{ Treatment } & \multicolumn{3}{|c|}{ Trial 1} & \multicolumn{3}{|c|}{ Trial 2} \\
\hline & \multirow[b]{2}{*}{ Mean } & \multicolumn{2}{|c|}{ Ratio to } & \multirow[b]{2}{*}{ Mean } & \multicolumn{2}{|c|}{ Ratio to } \\
\hline & & Control & MI & & Control & MI \\
\hline Control & $3.2(1.0,10.4)$ & - & 0.1 & $19.8(11.9,33.0)$ & - & 0.3 \\
\hline methyl isonicotinate & $35.2(12.5,99.2)$ & 11.0 & - & $71.4(44.7,114.1)$ & 3.6 & - \\
\hline cis-jasmone & $2.8(0.8,9.3)$ & 0.9 & 0.1 & - & - & - \\
\hline methyl jasmonate & $3.4(1.1,11.0)$ & 1.1 & 0.1 & - & - & - \\
\hline Y-decalactone & $16.2(5.7,46.5)$ & 5.1 & 0.5 & - & - & - \\
\hline methyl anthranilate & $7.4(2.5,22.1)$ & 2.3 & 0.2 & - & - & - \\
\hline$\delta$-decalactone & $19.0(6.7,54.3)$ & 5.9 & 0.5 & - & - & - \\
\hline $\begin{array}{l}\text { 2-isobutyl-3- } \\
\text { methoxypyrazine }\end{array}$ & - & - & - & $18.6(11.1,31.1)$ & 0.9 & 0.3 \\
\hline 6-amyl-alpha-pyrone & - & - & - & $15.6(9.2,26.4)$ & 0.8 & 0.2 \\
\hline methyl pyrazinoate & - & - & - & $41.8(25.9,67.6)$ & 2.1 & 0.6 \\
\hline ethyl nicotinate & - & - & - & $41.4(25.6,66.9)$ & 2.1 & 0.6 \\
\hline
\end{tabular}


Table 4 Mean number of western flower thrips females per trap (95\% CI) and ratios of mean counts to Control or methyl isonicotinate (MI) in Spain (nectarine orchard) trials. Bold ratios are larger $(\mathrm{P}<0.05)$ and italic ratios are smaller $(\mathrm{P}<0.05)$ than Control or MI.

\begin{tabular}{|c|c|c|c|c|c|c|}
\hline \multirow[b]{3}{*}{ Treatment } & \multicolumn{3}{|c|}{ Trial 1} & \multicolumn{3}{|c|}{ Trial 2} \\
\hline & \multirow[b]{2}{*}{ Mean } & \multicolumn{2}{|c|}{ Ratio to } & \multirow[b]{2}{*}{ Mean } & \multicolumn{2}{|c|}{ Ratio to } \\
\hline & & Control & MI & & Control & $\mathrm{MI}$ \\
\hline Control & $1.8(0.5,7.1)$ & - & 0.1 & $8.4(4.4,16.0)$ & - & 0.3 \\
\hline methyl isonicotinate & $20.6(6.5,65.5)$ & 11.5 & - & $28.6(16.1,50.9)$ & 3.4 & - \\
\hline cis-jasmone & $1.0(0.2,4.6)$ & 0.6 & 0.0 & - & - & - \\
\hline methyl jasmonate & $1.0(0.2,4.6)$ & 0.6 & 0.0 & - & - & - \\
\hline$\gamma$-decalactone & $11.2(3.5,36.2)$ & 6.2 & 0.5 & - & - & - \\
\hline methyl anthranilate & $2.8(0.8,10.1)$ & 1.6 & 0.1 & - & - & - \\
\hline$\delta$-decalactone & $11.3(3.5,36.3)$ & 6.3 & 0.5 & - & - & - \\
\hline $\begin{array}{l}\text { 2-isobutyl-3- } \\
\text { methoxypyrazine }\end{array}$ & - & - & - & $9.8(5.2,18.3)$ & 1.2 & 0.3 \\
\hline 6-amyl-alpha-pyrone & - & - & - & $8.4(4.4,16.1)$ & 1.0 & 0.3 \\
\hline methyl pyrazinoate & - & - & - & $12.3(6.2,24.2)$ & 1.5 & 0.4 \\
\hline ethyl nicotinate & - & - & - & $17.5(9.7,31.5)$ & 2.1 & 0.6 \\
\hline
\end{tabular}

Table 5 Mean number of western flower thrips males per trap (95\% CI) and ratios of mean counts to Control or methyl isonicotinate $(\mathrm{MI})$ in Spain (nectarine orchard) trials. Bold ratios are larger $(\mathrm{P}<0.05)$ and italic ratios are smaller $(\mathrm{P}<0.05)$ than Control or MI.

\begin{tabular}{|c|c|c|c|c|c|c|}
\hline \multirow[b]{3}{*}{ Treatment } & \multicolumn{3}{|c|}{ Trial 1} & \multicolumn{3}{|c|}{ Trial 2} \\
\hline & \multirow[b]{2}{*}{ Mean } & \multicolumn{2}{|c|}{ Ratio to } & \multirow[b]{2}{*}{ Mean } & \multicolumn{2}{|c|}{ Ratio to } \\
\hline & & Control & MI & & Control & MI \\
\hline Control & $0.4(0.1,2.7)$ & - & 0.1 & $6.6(3.5,12.6)$ & - & 0.3 \\
\hline methyl isonicotinate & $4.0(1.2,13.6)$ & 10.1 & - & $21.6(12.3,37.8)$ & 3.3 & - \\
\hline cis-jasmone & $0.2(0.0,2.4)$ & 0.5 & 0.0 & - & - & - \\
\hline methyl jasmonate & $1.0(0.2,4.4)$ & 2.5 & 0.2 & - & - & - \\
\hline Y-decalactone & $3.2(0.9,10.9)$ & 8.0 & 0.8 & - & - & - \\
\hline methyl anthranilate & $2.2(0.6,7.9)$ & 5.5 & 0.5 & - & - & - \\
\hline$\delta$-decalactone & $5.0(1.6,16.4)$ & 12.6 & 1.3 & - & - & - \\
\hline $\begin{array}{l}\text { 2-isobutyl-3- } \\
\text { methoxypyrazine }\end{array}$ & - & - & - & $4.4(2.2,8.9)$ & 0.7 & 0.2 \\
\hline 6-amyl-alpha-pyrone & - & - & - & $4.9(2.5,9.9)$ & 0.7 & 0.2 \\
\hline methyl pyrazinoate & - & - & - & $12.3(6.4,23.4)$ & 1.9 & 0.6 \\
\hline ethyl nicotinate & - & - & - & $9.8(5.3,17.9)$ & 1.5 & 0.5 \\
\hline
\end{tabular}


further eight thrips species (Teulon et al. 2011). This is also the first published report of MI increasing trap capture of Spanish WFT and OT populations.

The present study also widens the reported activity of another group of recently discovered thrips active volatile compounds, the lactones from ripening peach fruit (El-Sayed et al. 2014). While El-Sayed et al. (2014) found 6-amyl-apyrone (6-pentyl-2H-pyran-2-one) to be the most effective compound for increasing trap capture of the New Zealand flower thrips (Thrips obscuratus) in comparison to a range of other lactone compounds, the present results indicate that other lactone compounds may be better for other thrips species. $Y$-Decalactone and $\delta$-decalactone both increased WFT capture more than 6-amyl-a-pyrone, although not as much as MI (with one exception). Conversely, none of the lactone compounds tested in Spain increased trap capture of OT.

The ratios for the number of total thrips caught in traps with MI and Control traps in the New Zealand trials (Table 2) were lower than for similar ratios in the Spain trials (Table 3). Another study in Spain (M.M. Davidson, Plant
\& Food Research, unpublished data) has shown that the MI/Control ratio is similar (although total numbers differ) between sticky board and water traps in the same trial so trap type does not appear to influence this ratio. The different ratios may reflect specific characteristics of the different crops, their environments and the thrips complex present. In particular, the enclosed nature of the glasshouse may have allowed for contamination of the Control traps where odour from a MI baited trap influenced capture of thrips in the Control trap. This may have resulted in increased thrips capture in the Control traps and a lower MI/Control ratio. This may also be true for outdoor traps as far apart as $10 \mathrm{~m}$ (Teulon et al 2007b, 2014). Such an effect might be expected to be worse in greenhouses where the enclosed structure and relative lack of air movement would inhibit the dissipation of odours into the wider environment.

Based on these and other published results, MI remains the ai of choice for trapping WFT and OT, especially when they occur together, and possibly other thrips pest species, particularly in temperate conditions, due to its chemical attributes (e.g. volatility and stability) and its

Table 6 Mean number of onion thrips females per trap (95\% CI) and ratios of mean counts to Control or methyl isonicotinate $(\mathrm{MI})$ in Spain (nectarine orchard) trials. Bold ratios are larger $(\mathrm{P}<0.05)$ and italic smaller $(\mathrm{P}<0.05)$ than Control or MI.

\begin{tabular}{|c|c|c|c|c|c|c|}
\hline \multirow[b]{3}{*}{ Treatment } & \multicolumn{3}{|c|}{ Trial 1} & \multicolumn{3}{|c|}{ Trial 2} \\
\hline & \multirow[b]{2}{*}{ Mean } & \multicolumn{2}{|c|}{ Ratio to } & \multirow[b]{2}{*}{ Mean } & \multicolumn{2}{|c|}{ Ratio to } \\
\hline & & Control & MI & & Control & MI \\
\hline Control & $0.8(0.2,3.6)$ & - & 0.1 & $1.6(0.7,3.5)$ & - & 0.1 \\
\hline methyl isonicotinate & $9.3(3.5,25.1)$ & 11.7 & - & $16.7(12.0,23.1)$ & 10.4 & - \\
\hline cis-jasmone & $1.0(0.2,4.1)$ & 1.2 & 0.1 & - & - & - \\
\hline methyl jasmonate & $0.8(0.2,3.6)$ & 1.0 & 0.1 & - & - & - \\
\hline$\gamma$-decalactone & $1.3(0.3,5.0)$ & 1.6 & 0.1 & - & - & - \\
\hline methyl anthranilate & $2.0(0.6,6.5)$ & 2.5 & 0.2 & - & - & - \\
\hline$\delta$-decalactone & $1.5(0.4,5.3)$ & 1.8 & 0.2 & - & - & - \\
\hline $\begin{array}{l}\text { 2-isobutyl-3- } \\
\text { methoxypyrazine }\end{array}$ & - & - & - & $2.4(1.2,4.6)$ & 1.5 & 0.1 \\
\hline 6-amyl-alpha-pyrone & - & - & - & $0.4(0.1,2.0)$ & 0.3 & 0.0 \\
\hline methyl pyrazinoate & - & - & - & $3.3(1.7,6.2)$ & 2.0 & 0.2 \\
\hline ethyl nicotinate & - & - & - & $9.1(6.2,13.3)$ & 5.7 & 0.5 \\
\hline
\end{tabular}


relatively low toxicity profile to mammals (Acros Organics 2014; D.A.J. Teulon, Plant \& Food Research, unpublished data).

\section{ACKNOWLEDGEMENTS}

We thank Angela Eng and Stuart Attwood (Southern Paprika Ltd, Warkworth) for their help and collaboration on the project. We also thank the nectarine grower in Spain and Dr Jordi Riudavets at IRTA, Cabrils, Spain, for help with this research. Lee-Anne Manning (PFR) assisted us with sourcing the lactone compounds. Dr Rob van Tol (Plant Research International, the Netherlands) provided useful comments on an early draft. This work was funded through the MBIE Pre-Seed Accelerator Fund and Plant \& Food Research Core funding and was part of the European Australasian Thrips Semiochemical (EATS) Network supported by a Marie Curie International Research Staff Exchange Scheme (IRSES) Fellowship with the $7^{\text {th }}$ European Community Framework Programme and a NZ-EU IRSES Counterpart Fund PIRSES-CA-2011-295194 administered by the Royal Society of New Zealand.

\section{REFERENCES}

Acros Organics 2014. www.acros.be/ DesktopModules/Acros_Search_Results/ Acros_Search_Results.aspx?search_type= CatalogSearch\&SearchString=methyl $\% 20$ isonicotinate (accessed 19 May 2014).

Broughton S, Harrison J 2012. Evaluation of monitoring methods for thrips and the effect of trap colour and semiochemicals on sticky trap capture of thrips (Thysanoptera) and beneficial insects (Syrphidae, Hemerobiidae) in deciduous fruit trees in Western Australia. Crop Protection 42: 156-163.

Davidson MM, Butler RC, Winkler S, Teulon DAJ 2007. Pyridine compounds increase trap capture of Frankliniella occidentalis (Pergande) in a covered crop. New Zealand Plant Protection 60: 56-60.

Davidson MM, Perry NB, Larsen L, Green VC, Butler RC, Teulon DAJ 2008. 4-pyridyl carbonyl compounds as thrips lures: effectiveness for western flower thrips in Y-tube bioassays. Journal of Agricultural \& Food Chemistry 56: 6554-6561.
El-Sayed AM, Mitchell VJ, McLaren GF, Manning LM, Bunn B, Suckling DM 2009. Attraction of New Zealand flower thrips, Thrips obscuratus, to cis-jasmone, a volatile identified from Japanese honeysuckle flowers. Journal of Chemical Ecology 35: 656-663.

El-Sayed AM, Mitchell VJ, Suckling DM 2014. 6-Pentyl-2H-pyran-2-one: a potent peachderived kairomone for New Zealand flower thrips, Thrips obscuratus. Journal of Chemical Ecology 40: 50-55.

GenStat Committee 2013a. GenStat Reference Manual Release 16 - 3, Procedure Library PL22. VSN International, Oxford.

GenStat Committee. 2013b. The Guide to GenStat Release 14 - Parts 1-3. VSN International, Oxford.

Hamilton JGC, Hall DR, Kirk WDJ 2005. Identification of a male-produced aggregation pheromone in the western flower thrips Frankliniella occidentalis. Journal of Chemical Ecology 31: 1369-1379.

Koppert 2014. LUREM-TR. www.koppert.com/ products/monitoring (accessed 15 April 2014).

McCullagh P, Nelder JA 1989. Generalized Linear Models, 2nd ed. Chapman \& Hall, London, UK.

Mound LA, Walker AK 1982. Terebrantia (Insecta: Thysanoptera). Fauna of New Zealand 1. Science Information Publishing Centre, Wellington. Pp. 1-113.

Moritz GM, Mound LA, Morris DC, Goldarazena A 2004. Pest thrips of the world: visual and molecular identification of pest thrips (CD-ROM), CBIT, University of Brisbane, Australia.

Muntyan EM, Il'ev PB, Batko MG, Yazlovetsky IG 2013. Use of attractants for the control of Thrips tabaci Lind. (Thysanoptera: Thripidae) on onion in the greenhouse. Agrokhimiya 4: 69-75 (in Russian; Chemical Abstracts Number CAN160:144548).

Murai T, Imai T, Maekawa M 2000. Methyl anthranilate as an attractant for two thrips species and the thrips parasitoid Ceranisus menes. Journal of Chemical Ecology 26: 25572565. 
Niassy S, Maniania NK, Subramanian S, Gitonga LM, Ekesi S 2012. Performance of a semiochemical-baited autoinoculation device treated with Metarhizium anisopliae for control of Frankliniella occidentalis on French bean in field cages. Entomologia Experimentalis et Applicata 142: 97-103.

Penman DR, Osborne GO, Worner SP, Chapman RB, McLaren GF 1982. A chemical attractant for Thrips obscuratus (Thysanoptera: Thripidae) in stonefruit in New Zealand. Journal of Chemical Ecology 8: 1299-1303.

Pherobank 2013. Pherobank catalogue. http://www.pherobank.com/Documents/ Pherobank\%20catalogue\%202013.pdf (accessed 15 April 2014).

Sampson C, Kirk WDJ 2013. Can mass trapping reduce thrips damage and is it economically viable? Management of the western flower thrips in strawberry. PLoS ONE 8(11): e80787. doi:10.1371/journal.pone.0080787.

Teulon DAJ, Penman DR, Ramakers PMJ 1993. Volatile chemicals for thrips (Thysanoptera, Thripidae) host-finding and applications for thrips pest-management. Journal of Economic Entomology 86: 1405-1415.

Teulon DAJ, Davidson MM, Hedderley DI, James DE, Fletcher CD, Larsen L, Green VC, Perry NB 2007a. 4-pyridyl carbonyl and related compounds as thrips lures: effectiveness for onion thrips and New Zealand flower thrips in field experiments. Journal of Agricultural \& Food Chemistry 55: 6198-6205.
Teulon DAJ, Butler RC, James DE, Davidson MM 2007b. Odour-baited traps influence thrips capture in proximal unbaited traps in the field. Entomologia Experimentalis et Applicata 123: 253-262.

Teulon DAJ, Davidson MM, Perry NB, Nielsen M-C, van Tol RWHM, de Kogel WJ 2011. Recent developments with methyl isonicotinate, a semiochemical used in thrips pest management. New Zealand Plant Protection 64: 287 (abstract only).

Teulon DAJ, Davidson MM, Butler RC, Nielsen M-C 2014. Effect of release rate and odour cross-contamination for semiochemical baited traps used in thrips pest management. IOBC/WPRS Working Group 'Integrated Control in Glasshouses'. Ghent, Belgium. IOBC/WPRS Bulletin 102: in press.

Wogin MJ, Butler RC, Teulon DAJ, Davidson MM 2010. Field response of onion thrips and New Zealand flower thrips to single and binary blends of thrips lures. Canadian Entomologist 142: 75-79. 